\title{
Tecnologías de género, discurso homofóbico y prácticas de resistencia
}

\author{
María Camila Cordero Polanía \\ Estudiante de Psicología \\ Universidad Surcolombiana, Colombia \\ macamicordero@gmail.com
}

Gran parte de mi interés y motivación al escribir el presente ensayo se debe a su carácter identificativo, ya que me siento parte de un sector que día a día reclama su espacio a pesar de haber sido segregado, humillada e ignorada a lo largo de la historia de nuestro país. Hablo de la comunidad LGTB. Es por esto que deseo hablar de las causas y consecuencias de las diferentes agresiones y sanciones a las que nos hemos visto sometidos y también de los procesos discursivos y de resistencia desarrollados por nuestra comunidad.

Es de igual manera importante para mí dar cuenta del carácter opresivo y discriminativo del discurso homofóbico que opera desde diferentes dimensiones como la moral, la religiosidad y la educación. Asimismo, otra de mis pretensiones está encaminada a manifestar y analizar la manera en que dicho discurso tiene una repercusión ambivalente en nuestra comunidad, evidenciando los estragos a nivel psicológico y físico de quienes lo hemos padecido y también la manera en que desde la humillación e insignificancia hemos respondido y resistido a este particular acto.

Apoyándome en los estudios de la Teoría Queer pretendo desarrollar argumentos que demuestren la manera en que las distintas "tecnologías de género" han sido usadas tradicionalmente de forma totalmente impositivas e inhibidoras. Por "tecnologías de género" debemos entender no solo las técnicas sino los medios y formas discursivas en que se producen y reproducen las distintas normas o estilos de vida basados en una ideología determinada, de la hegemonía dominante.
La teoría Queer surge principalmente en un contexto norteamericano en los años 90 y se encuentra íntimamente relacionada con los estudios feministas y de la comunidad LGTB, por la razón común de que en todos ellos se discute la conformación hegemónica de las identidades y se busca reformular procesos diferentes y nuevos respecto a la identificación y la diferenciación en torno a la sexualidad.

El nombre con que se le ha designado a esta teoría es constantemente (aunque cada vez menos) usado de manera peyorativa hacia las personas con identidades sexuales y de género emergentes, especialmente hacia la comunidad homosexual, debido a que esta palabra significa "desviado", "extraño" lo cual es contrario a lo que sería heterosexual (straight) que significa "derecho".

Fueron muchos y diversos los hechos que precedieron esta teoría y que posibilitaron su surgimiento, a continuación, expongo algunos de ellos:

- El desarrollo de nuevas teorías sobre la sexualidad, por ejemplo, la propuesta por Foucault (1976), que presenta una aproximación a los problemas teóricos que ha supuesto el excesivo control "de la hipócrita sociedad burguesa" sobre la sexualidad, a través del discurso que se consolida como argumento de uso normativo para forjar el dispositivo de sexualidad que nos gobierna, además de ser su principal referente de regulación (Fernández, 2010).

- Los diferentes descubrimientos sobre la tolerancia a la homosexualidad, desde la antigüedad hasta la edad media, Boswell (1980), 
este autor denuncia la actitud negativa que ha concebido la iglesia, después del siglo Xll, sobre la homosexualidad. Antes de este siglo en la antigua iglesia católica existió la Adelfopoiesis, práctica que consistía en unir por medio de una ceremonia a dos personas del mismo sexo que generalmente eran hombres.

- Las evidencias arqueológicas de comportamientos homosexuales en la Grecia Antigua, registradas por Dover (1978), que se hicieron famosas y obtuvieron gran reconocimiento debido a la rigurosidad de su estudio, ya que su autor se encargó de recoger cientos de testimonios procedentes de la cultura material como las pinturas vasculares o grafitos, del ámbito jurídico como los procesos judiciales y del mundo literario desde Aristófanes a Platón.

- La aparición de artículos sobre el tema de la heterosexualidad obligatoria, como los de Rich (1980), donde la autora afirma que la heterosexualidad no es algo natural ni intrínseco en los valores humanos, sino una institución impuesta en muchas culturas y sociedades en las que la mujer vive subordinada por el hombre, este ensayo anima a feministas heterosexuales a analizar la heterosexualidad como institución política que debilita a las mujeres, y a cambiar esta realidad.

- El importante cambio social surgido a partir de los movimientos en favor de los derechos de las mujeres y homosexuales, además de la lucha contra el SIDA y el advenimiento en las ciencias de otros investigadores diferentes a los tradicionales $\mathrm{y}$, por último, pero no de menos importancia, el evidente y creciente interés de las universidades de Estados Unidos como Columbia, Duke y Nueva York, por estudiar las sexualidades, interés que posteriormente se expande a otras universidades en países como España, Colombia, Brasil y México.

Quisiera detenerme con mayor atención en este último hito, ya que me parece importante comentar la razón principal y urgente del interés aparentemente repentino de la academia en los estudios de gays y lesbianas. Ocurre que hasta entonces este tipo de estudios no eran abordados en las universidades sino fuera de ellas, publicándose en editoriales comerciales. La razón obedece a la unión de la militancia de varios grupos que protestaban la falta de atención a la epidemia del SIDA en Estados Unidos, formándose alrededor de 1990 en Nueva York, Queer Nation, grupo de desobediencia civil constituido mayoritariamente por hombres homosexuales y también por lesbianas, bisexuales, transgéneros, entre otros, quienes se convirtieron en sus aliados. Ante los efectos más nefastos de la homofobia durante la epidemia del SIDA, estas personas asumen una nueva conciencia política que los impulsa a organizarse y defenderse.

El objetivo principal de Queer Nation fue la eliminación de la homofobia poniendo en discusión, interrogando y rechazando de manera radical el binomio universal de género y sexo, las clasificaciones de identidad sexual y desafiando a las diferentes instituciones que ayudaban a reproducir las categorías sexuales, la exigencia de derechos y sus garantías estaba en segundo plano. Es por esto que el impacto que generó en la comunidad estadounidense fue tan polémico y significativo, ya que este grupo de disidentes usaba métodos de acción directa para ser notados. Entre ellos tenemos las llamadas y populares "Queer nights out" (salidas nocturnas maricas) donde los homosexuales salían a bares que no eran de ambiente gay para hacerles ver a los demás que ya no iban a seguir ocultándose en determinados lugares para hacer vida social y darse muestras de afecto, o como el aún más controversial "outing", que hace referencia a la práctica de sacar del armario a otra persona haciendo pública su homosexualidad.

Con esto, los integrantes de Queer Nation pretendían demostrar que personajes "importantes" como políticos y figuras del entretenimiento eran parte de ellos, así les conviniera esconderlo. También acudieron al uso de frases y lemas muy claros y directos como "hate straight" (Odio a los heterosexuales)" o "We're here. We're queer. Get used to it" (Estamos aquí. Somos diferentes. Acostúmbrense) en cada una de sus manifestaciones. A pesar de que Queer Nation duró poco, como organización activa dejó 
un impacto fuerte a nivel cultural e investigativo, y se considera de gran importancia el efecto duradero que tuvo en la política de identidad sexual en los Estados Unidos.

Una de las pioneras y más reconocidas autoras de esta teoría es Butler (1990), quien con su libro "El género en disputa" permite la ampliación de un campo investigativo en torno a la concepción de género, considerándolo como performativo. Esto quiere decir, que los diferentes roles o rituales que se tengan en torno al género son el efecto de la repetición de un grupo de significaciones, instituciones y normas que son establecidas por la sociedad a través del lenguaje y de su historia, por lo tanto, es imposible pensar en el género como algo natural, fijo y permanente. Es precisamente esta performatividad la que va a poner en evidencia su carácter continuo, variable, imitativo, representativo y autorepresentativo, que depende y muta según el contexto y el tiempo en el cual nos encontremos.

Otro de los grandes aportes que hace esta autora a la T.Q es el planteamiento de una "matriz heterosexual", que puede ser entendida como un todo de varios elementos de carácter cultural que, por medio de ciertas prácticas y discursos, tiene como finalidad producir, reproducir y perpetuar la heterosexualidad. Dicha matriz se basa principalmente en la diferenciación de las personas, de los sexos y no en lo que nos hace comunes.

En el mismo año de publicación de "El género en disputa", otra autora, Sedgwick (1990), publica "Epistemología del armario", otro clásico de la teoría Queer, donde la autora menciona varias ideas interesantes en relación con la decisión de confesar la identidad sexual. Ella sostiene que estar en el armario no es meramente personal, ya que puede contar con la colaboración o la no-colaboración de los integrantes del entorno. También manifiesta su rechazo a continuar el debate permanente entre el constructivismo y el esencialismo por considerarlo políticamente poco productivo, pero, a mi modo de ver, el aporte más interesante que hace a la teoría Queer es plantear la necesidad de desarrollar discursos anti-homofóbicos y críticos, pero teniendo en cuenta su especificidad teórica, la cual debe proceder desde la particularidad de ser homosexual.

Bajo el nombre de "teoría torcida" la T.Q llega al contexto hispanohablante, Llamas (1998), hace su aporte nuevo a esta teoría comentando que poderes como la represión y la libertad influyen directamente en la construcción de la sexualidad de una persona, además de comentar acerca de la existencia de un "régimen de la sexualidad" que puede entenderse como un modelo impositivo de la sociedad occidental, el cual establece dos roles/identidades que diferencian sexualmente a las personas y hace un critica a este régimen argumentando que no cubre el actual abanico de posibilidades de formas de ser de los individuos.

Sin duda alguna, son muchos y diversos los puntos de vista que nutren esta teoría de género, sin embargo, creo interesante profundizar en lo escrito por Lauretis (1889), para ir entendiendo el por qué hablo de mecanismo impositivo y perjudicial cuando hablo de tecnologías de género.

Para escribir sobre las tecnologías de género la autora se basa en Foucault (1976), acerca de la producción del cuerpo, o las tecnologías del sexo, las cuales tienen un nacimiento nuevo alrededor del siglo XV1ll. Antes de este siglo y especialmente para la época de los victorianos la sexualidad había sido vista de una manera puritana empero, para el autor, pese a que estas tecnologías no son del todo ajenas de la temática del pecado, escapaban en lo esencial a la institución eclesiástica. Por mediación de la medicina, la pedagogía y la economía, se hizo del sexo no sólo un asunto laico, sino un asunto "científico" y de Estado; aún más: un asunto en el cual todo el cuerpo social, y casi cada uno de sus individuos, era instado a vigilarse.

Para el filósofo y escritor francés, a partir del siglo XV1ll, en esta nueva tecnología del sexo se pueden distinguir cuatro grandes conjuntos estratégicos que se despliegan como dispositivos específicos de saber y poder:

- Histerización del cuerpo de la mujer: La mujer es el primer personaje invadido por el 
dispositivo de la sexualidad. Específicamente esa mujer que disfruta del tiempo libre, que puede rondar en los límites de lo "mundano" y a la que le es asignado un valor por su sexo junto con un montón de obligaciones maternales y conyugales, desencadenando así "la mujer nerviosa" que es la forma más visible de esta histerización. Como eje para su desarrollo la tecnología del sexo que vulneraba a la mujer se valió principalmente de la medicina, cuyo objetivo era la fisiología sexual de las mujeres.

- Pedagogización del cuerpo del niño: Inicialmente solo interesaba inculcarle las disciplinas del cuerpo al colegial burgués, quien tenía un deber moral y la obligación de mantener para su familia y su raza una "descendencia sana". Pero durante el curso del siglo XIX hubo una generalización en todo el cuerpo social del dispositivo de la sexualidad a partir de un foco hegemónico. Es entonces cuando se torna importante la educación sexual en el infante, reconociendo que es un ser sexual por naturaleza, pero paradójicamente prohibiendo y censurando la actividad sexual indebida por traer consigo riesgos físicos y morales, individuales y colectivos. Evidentemente el eje que avivó el desarrollo de esta tecnología fue la pedagogía, con su objetivo muy claro, la sexualidad específica del niño.

- Socialización de las conductas procreadoras: Se habla de tres procesos de socialización de estas conductas: a). socialización económica por el sesgo de todas las incitaciones o frenos aportados, por medidas "sociales" o fiscales, a la fecundidad de las parejas; b). socialización política por la responsabilización de las parejas respecto del cuerpo social entero (que hay que limitar o, por el contrario, reforzar) y c). socialización médica, en virtud del valor patógeno, para el individuo y la especie, prestado a las prácticas de control de los nacimientos. El eje de desarrollo en el que se basó esta tecnología fue la demografía, cuyo objetivo era la regulación espontánea o controlada de los nacimientos

- Psiquiatrización del placer perverso: El sexo es entendido como una función biológica que cuenta con su aparato anatomofisiológico el cual le otorga una razón de ser, una finalidad. Pero, también el sexo es entendido como un instinto que mediante su propio desarrollo y de acuerdo con los tipos de objetos con los que pueda apegarse, puede ser susceptible de presentar anomalías constitutivas, desviaciones adquiridas o conductas perversas.

Es importante mencionar que la familia como instancia de control juega un papel determinante en cada uno de estos dispositivos, ya que fue en primer término en la familia "burguesa" o "aristocrática" donde se le da una relevancia significativa al sexo, siendo este el elemento del cuerpo que más inquietó a estas familias, identificándose con él, incluso, sometiéndose a él, ya que le otorgaban al sexo un poder misterioso e indefinido, por lo tanto, peligroso. Sin embargo, el dispositivo de la sexualidad creado por la burguesía no repercutió en la clase proletaria de manera inmediata, sino tiempo después, cuando deciden poner la sexualidad como una ley social que debe ser cumplida, bajo los primeros ideales que tuvieron los burgueses de protección y cuidado de su cuerpo y su sexualidad, pero ahora sometidos al foco de la hegemonía dominante. En otros términos, lo biológico se ve reflejado en lo político, la vida como derecho fundamental se verá "amparada" por la ciencia y el conocimiento científico con la finalidad de convertir al saber-poder en un elemento clave para el control de las poblaciones $\mathrm{y}$ al ser la vida prioridad política, también lo fue el cuerpo. A esta serie de ideas fue a lo que Foucault llamó Biopolítica.

Ahora bien, recordemos que Lauretis (1989), se basa en Foucault para hablar sobre tecnologías de género, para ella es necesaria una deconstrucción de la mutua contención entre género y diferencias sexuales, ya que es solo esta diferencia sexual la que va a presuponer el género, desconociendo así las diferentes representaciones lingüísticas y culturales que también lo constituyen. Para tener un punto de arranque la autora propone pensar al género en paralelo con las líneas de la ya mencionada teoría de la sexualidad, pensarlo como una "tecnología del sexo". Al mismo tiempo propone que también el género, ya sea como representación o auto-representación, 
es el producto de varias tecnologías sociales, discursos institucionalizados, de epistemologías y de prácticas críticas, como de la vida cotidiana.

Si se quiere pensar al género en paralelo con la sexualidad es necesario entenderlos de la misma manera, esto sería pues, que el género al igual que la sexualidad, "es el conjunto de los efectos producidos en los cuerpos, los comportamientos y las relaciones sociales por cierto dispositivo dependiente de una tecnología política compleja." (Foucault, 1976, p 75). Y no algo originalmente existente en los seres humanos.

Las personas que leen este ensayo podrían pensar que las tecnologías del sexo son las mismas que las tecnologías de género más no es así, hablar de tecnologías de género resulta más amplio e incluyente, ya que para Foucault la sexualidad era una sola para hombres y mujeres, lo cual puede suponerse como masculina, a causa del contexto histórico en el cual el autor desarrollaba sus ideas. De esta manera al acuñarle lo que representa el género a las tecnologías del sexo es ir más allá de Foucault. En síntesis, se debe entender a las tecnologías del sexo como ese conjunto de técnicas, medios y formas de producir y reproducir normas de vida previamente pensadas e instauradas, a conveniencia por una hegemonía dominante, con la intención de seguir subordinado la clase trabajadora, pero que niega al género debido a su postura de la sexualidad androcéntrica. Y se debe entender a las tecnologías de género como el conjunto de técnicas, modos e instituciones que producen, reproducen y perpetúan la verdad acerca de la masculinidad y feminidad para así legitimar su normalización de manera coercitiva.

No es necesario hacer mayor esfuerzo pensando en posibles ejemplos que reflejen la veracidad de lo antes expuesto, ya que en la actualidad es muy evidente ver como distintas instituciones educativas, se encuentran regidas por unas normas tipo estándar muy arraigadas a la creencia colectiva y cultural de las normas de género y los roles inamovibles que estas representan. De esta manera no supone extrañeza, por un lado, la censura de cabellos largos, aretes o uniformes ajustados para los hombres, y, por otro, para las mujeres, las "malas palabras" y posiciones inadecuadas al sentarse, comportamientos que corrigen los educadores hasta el cansancio. También es evidenciable la manera en que este entorno escolar constriñe el derecho a la libre expresión de la personalidad, no solo en sus estudiantes, sino que, además y de manera más estricta, en sus docentes.

Recientemente en una institución educativa de una ciudad de nuestro país se vulneraron los derechos de estudiantes y docentes, como se puede leer en el periódico El Espectador (El trascendental caso de una profesora trans en colegio del Valle del Cauca, 2018) se les negó el derecho a la educación a unos menores de grado quinto de primaria y al mismo tiempo se le negó el derecho al trabajo y al desarrollo de su libre personalidad a una docente, solamente por hacer manifiesta su identidad de género. Según esta notica, son los padres de familia (no por nada lo referenciaba Foucault como una de las instancias de control más importantes en la sociedad) quienes se oponen a capa y espada al desarrollo normal de las clases de Lengua Castellana en el colegio La Inmaculada, en Tuluá, al grado tal de redactar una carta grupal dirigida a la Secretaria de Educación exigiendo el cambio de profesor en la institución. Argumentaron que sus hijos llegaron a casa muy "traumatizados" y extrañados al ver a una persona vestida de hombre que dice ser mujer $\mathrm{y}$, adicional a la carta, decidieron no llevar a sus hijos más al colegio hasta que se efectuara el cambio solicitado. Y lo consiguieron.

La mismísima Secretaria de Educación ignora la sentencia C-481 de 1998 de la Corte Constitucional, al efectuar el cambio solicitado. Lo anterior pone en evidencia el completo desconocimiento que tiene el sistema educativo de nuestro país de los derechos de las personas LGTB. La profesora transgénero, Andrea Gómez, quien tiene 58 años de los cuales 24 ha dedicado a la enseñanza de niños en la zona rural del país, no alcanzó a dar ni su primera clase en la ciudad y ya es re victimizada por los padres de familia de este colegio. La profesora había llegado a la ciudad en busca de seguridad y nuevos proyectos 
laborales debido a un intento de homicidio en su contra, por la misma cuestión de su identidad de género. Entonces, del peligro de muerte se pasa al rechazo y al repudio. Andrea aún sigue con vida, pero les aseguro que ya le han matado mucho por dentro.

Otra tecnología de género es el cine o aparato cinemático, explica Lauretis (1989). Por medio de este aparato cinemático no solo se construyen y reproducen las representaciones del género, sino que también estas representaciones son asimiladas subjetivamente por cada individuo al que esa tecnología se dirige. Este proceso de asimilación subjetiva puede relacionarse íntimamente con el concepto propuesto por Althusser como interpelación, que "es el proceso por el cual una representación social es aceptada y absorbida por un individuo como su propia representación y así volverse, para ese individuo, real, aun cuando es imaginaria"' (Lauretis, 1989, p. 19). Para entender este proceso de asimilación subjetiva en el cine la clave está en el concepto de espectador/a generizado, esto quiere decir, los modos y formas en las cuales cada espectador/a individual es apelado por el film, la manera en la cual su identificación ya sea femenina o masculina se va a ver representada en la película. Lo anterior responde a una representación ideológica del género que se da en el cine y que de manera cada vez más llamativa y normalizada se adentra en nuestros modos y formas y ser y pensar, alejándonos un poco más de otras maneras de construir historia y autenticidad.

Es que hasta en los baños públicos de los diferentes espacios de esparcimiento social se ven reflejadas estas tecnologías, Beatriz Preciado dedica algunas páginas a (Preciado, s.f.) para manifestárnoslo, y cualquiera de nosotros lo puede confirmar, y es que aunque aparentemente la arquitectura de los baños responde a las diferencias de las funciones naturales y esenciales del cuerpo humano, su funcionalidad responde a la de una verdadera prótesis de género, la cual va no solo a producir sino también a fijar estas diferencias en las funciones biológicas (Preciado, S.f). En otras palabras, el diseño arquitectónico de los baños escuda bajo el pilar de la separación de funciones biológicas diferentes, su real función, la cual consiste en inspeccionar y evaluar de manera pública la validez de cada cuerpo según las normas establecidas para lo masculino y femenino.

Se vuelve aún más razonable lo expresado por Preciado si se piensa en las ventajas que sugiere ir en contra posición de esta "lógica de los baños" y la manera en que es rechazada por el público masculino por poner en riesgo lo que supone su género. Por ejemplo, en un artículo del periódico El Universal de la ciudad de Cartagena (Estudios demuestran que orinar sentado beneficia la salud de los hombres, 2015) se advierte a los hombres de los beneficios que sugiere para su salud el prescindir de usar los llamados orinales para orinar de pie y mejor usar el retrete y orinar sentados, al igual que las mujeres. Tal y como lo indican los investigadores del Departamento de Urología del Leiden University Medical Center (LUMC), en Holanda, se dice que ayuda a evitar problemas de próstata pues, al estar sentado, el hombre se puede relajar y no se apura para eliminar la orina y de esta manera no se tensionan los músculos de la vejiga.

Para darle fin a este apartado, y con base en los ejemplos anteriores, se puede dar cuenta del modo imperativo en que las diferentes tecnologías del género funcionan y constriñen al ser humano hasta el punto de la marginalización, del señalamiento social y la agresión para aquellos seres disidentes que trasgreden dichas tecnologías "sutilmente" establecidas en la sociedad como naturales y verdaderas. En este sentido, ¿Cómo puede un ser humano desarrollarse de manera autónoma y libre si se ve limitado desde su nacimiento por el simple hecho de tener cierto tipo de genitales $\mathrm{u}$ otros? Se nos vuelve urgente y necesaria la deconstrucción de estas tecnologías por unas que legitimen la diversidad sexual y de género, unas tecnologías capaces de funcionar con un sujeto que es como eje.

Para ahondar en la hipótesis central de este ensayo, en las siguientes páginas describiré las diferentes afectaciones que tiene sobre nuestra comunidad la ideología heteropatriarcal y heterosexista. 
Para empezar, es adecuado precisar que esta lógica heterosexista no solo desconoce y rechaza profundamente lo que difiere de ella, sino que tampoco logra entender esta diferencia y quizá a ello se deba tanto miedo disfrazado de odio. De esta manera, el temor a lo desconocido va a suponer en estas personas un estado de alerta, dispuestos a atacar si se sienten bajo amenaza.

La homofobia, entendida como el miedo irracional o aversión hacia las personas homosexuales, que puede desencadenar en actos violentos (físicos, verbales) o marginación social hacia los mismos (García, s.f, p.30), es la principal consecuencia de un pensamiento heterosexista que busca perpetuar la convicción de la heterosexualidad como algo totalmente natural y normal, afectando así profundamente a nuestra comunidad, ya que al normalizarse en la sociedad este pensamiento sobre la sexualidad, las personas que no encajamos, que diferimos y que a pesar del miedo y el estigma luchamos por ser, somos señaladas, objeto de burlas y percibidas como personas enfermas y perversas.

Debido a que nuestra comunidad no la conformamossolamentepersonashomosexuales, propongo de ahora en adelante concebir lo que se entiende por homofobia como LGTBfobia, esto con la intención de dejar claro que los homosexuales no somos los únicos afectados con los diferentes actos despectivos de aquellas personas a las que les cuesta aceptar y respetar la diversidad. La transfobia suele expresarse incluso de manera más violenta y cruda que la homofobia, el odio disfrazado de miedo es tan bárbaro que, según el "registro de violencia" (Comisión Interamericana de derechos humanos, 2015), se destaca que el $80 \%$ de las mujeres trans latinoamericanas mueren a los 35 años o menos, estamos hablando de una expectativa de vida de solo 35 años, en comparación con la expectativa de una mujer heterosexual latinoamericana que, según el periódico La Nación, llega a los 74 años (La esperanza de vida en Latinoamérica llegó a los 74 años, 2017).

Quisiera mencionar que se identifican cinco tipos de homofobia según Maroto (2006): Homofobia cultural, institucional, personal, interpersonal e internalizada; cada una de ellas se pueden evidenciar diariamente en nuestra sociedad y cada una tiene cierta repercusión especial hacia quien es dirigida, sin embargo, antes de hablar de las afectaciones reales y crudas que sufrimos por causa de este fenómeno, analizaré los diferentes conjuntos de estrategias de las que se vale este discurso homofóbico para perpetuarse y cada vez ganar más adeptos.

Una de las principales instituciones donde opera este discurso es en las religiones, especialmente en la religión católica- cristiana, la que me interesa referenciar, esto a causa de pertenecer a una sociedad donde la mayor parte de la población asiste a misa cada ocho días sin falta, creen con fervor ciego en un salvador, predican el "buen camino" de la vida y no hacen sino destruir o entorpecer el "camino diferente" de otras personas.

En su documento (la Congregación para la Doctrina de la fe, 1986), el Vaticano hace referencia a los actos de homosexualidad como algo desordenado intrínsecamente, y que no puede, sin excepción, recibir aprobación alguna. Los actos de homosexualidad son reprochables por considerarse anti-natura, ya que la iglesia cree, por designio de su Dios, que la sexualidad humana debe relacionarse con el acto conyugal el cual tiene dos principales y únicos sentidos, el primero, es el significado unitivo y, el segundo, el significado procreador. De esta manera, se considera pecado todo acto que separe en la sexualidad los dos aspectos señalados. La actividad homosexual no expresa una unión complementaria, capaz de transmitir la vida $\mathrm{y}$, por lo tanto, contradice la vocación a una existencia vivida en esa forma de auto-donación que, según el Evangelio, es la esencia misma de la vida cristiana. Desde allí se justifica la discriminación.

Esto quiere decir, que la valoración moral de la homosexualidad en nuestra sociedad va a depender en gran medida de los diferentes dogmas que rigen esta religión. Estas posturas que vienen de la intolerancia y la concepción reduccionista y satanizada de la sexualidad humana son las que van a verse legitimadas en 
nuestra sociedad, desconociendo otras posturas diferentes acerca de este tema. Negando la diversidad humana como una cuestión de derechos humanos, reduciendo estos derechos solo a los heterosexuales.

Para analizar la dimensión educativa se debe entender a las instituciones escolares no solo como una tecnología de género, como ya lo había aclarado, sino además como un ente perpetuador, reproductor y regulador de la sexualidad y los valores morales humanos. A pesar de la existencia de diversos modelos pedagógicos críticos en los cuales pueden apoyarse las instituciones educativas para impartir sus lecciones, lastimosamente, aún en nuestros días, se educa bajo un modelo pedagógico tradicional que se caracteriza principalmente por entender a la educación técnica y cognitiva como el fin fundamental de la enseñanza.

Donde el rol del maestro autoritario es determinante, y el estudiante es visto como una hoja de papel en blanco, la cual debe llenarse a través de un aprendizaje autoritario y repetitivo (Blanco, 2000). En este sentido, se limita al estudiante desconociendo que es un ser senti-pensante y que necesita de una educación integral para no solo aprender las lecciones sino aprehenderlas. En esa integralidad las dimensiones éticas y afectivas son imprescindibles para vivir en el respeto por las diferencias, como las de orientación sexual. Sin integralidad, la educación tradicional insistirá en enseñarles a las personas que biológica y culturalmente solo se puede ser hombre o mujer y que cualquier ambigüedad de género sugiere una trasgresión perversa inadmisible.

Como se puede ver, el tema de la homofobia y las diferentes maneras en que es expresada es bastante amplio, podría combatirse desde una escuela crítica, pero, al contrario, una escuela tradicional, la estimula, en todas sus formas, como las siguientes. La personal, cuando existe la convicción individual en cada quien de que las personas que no son heterosexuales son inferiores a los que sí lo son. Identifico este tipo de homofobia en algunas amistades que consolidé antes de salir del closet, amistades que, aunque no se han perdido sufrieron una notable ruptura, ya que no resulta cómodo construir historia al lado de personas que, aunque te estimen, consideren que estas mal. Amistades que guardan las esperanzas de que algún día vuelvas a ser la de antes, es decir, heterosexual, ya que perciben la desviación en la orientación sexual como algo transitorio. Este tipo de cosas lastiman, ya que no hay una total aceptación por parte del otro, solo existen prejuicios personales escudados en una falsa "tolerancia".

La homofobia se expresa también de manera interpersonal, cuando la personal (prejuicio) afecta de manera directa las relaciones humanas, transformando los prejuicios que se tenían en un componente activo y directo de discriminación, esto tiene que ver con la trascendencia del pensar al actuar, entonces, ya no es: "pienso que no está bien la manera en la que ejerces tu sexualidad pero lo tolero" sino: "no quiero que nos vean juntas, pueden pensar que somos iguales" o "no hay problema en que seas lesbiana siempre y cuando no te vayas a enamorar de mí" o " ¿si te gustan tanto las mujeres por qué sales con chicas que se ven como hombres? Pero la violencia no es solamente verbal, sino que muchas veces es física. Según los casos atendidos por (Defensoría del Pueblo, 2016), el porcentaje más alto de los casos corresponden con este tipo de homofobia, donde el $38 \%$ de las personas que denunciaron lo hicieron debido a la discriminación, y el 10\% por agresiones que implican, desde lesiones personales a tentativa de homicidio.

La escuela tradicional impulsa, además, la homofobia institucional, la que se expresa por medio de las diferentes normas y leyes que establecen políticas, recursos o reglas en las que los gobiernos, industrias, iglesias, instituciones escolares, centrosmédicoseincluso profesionales, discriminan sistemáticamente sobre las bases de la identidad y orientación sexual de los demás. Según (Defensoría del Pueblo, 2016) se triplicaron los números de víctimas de abuso a raíz de su identidad u orientación de sexual, en nuestro país, en el año 2016 con relación al año 2015. El informe indica que el 30\% de las denuncias presentadas en el 2016 fueron a causa de la homofobia institucional. A mi modo de 
ver, este tipo de homofobia requiere de una pronta y efectiva intervención, ya que, si bien se quiere exterminar la homofobia y los crímenes de odio, es urgente y necesario que desde la institucionalidad y el gobierno se garanticen los derechos humanos de cada uno de nosotros y no que, por el contrario, como es común ver, se nos invisibilice o lo que es peor, se nos discrimine.

Discriminación que puede verse en los diferentes servicios de salud, los cuales no responden a las necesidades de toda la población, en especial de las personas trans, y ni que hablar de lo corto que se quedan en materia de salud sexual hacia las mujeres lesbianas y bisexuales. $\mathrm{O}$ como podría verse también en el constante abuso policial, donde los uniformados homofóbicos aprovechan el poder que les otorga la institucionalidad para atentar contra nuestra comunidad, mediante las detenciones arbitrarias, la aplicación selectiva de la ley, los actos abusivos y aplicación de prejuicios para restringir el acceso y circulación en espacios públicos de homosexuales.

Igual sucede con la homofobia cultural, expresada por medio de las normas o códigos sociales de comportamiento que, si bien no están escritos en leyes, que busca legitimar la opresión de las minorías, en este caso, todas aquellas personas que no se acojan al régimen de la heterosexualidad. Este tipo de homofobia es simbólica, caracterizada por agredirnos "sutilmente", en las diferentes descalificaciones instaladas en nuestro lenguaje, las bromas y la ridiculización.

La escuela tradicional promueve también, de modo preocupante, la homofobia que se expresa de manera internalizada, por el mismo homosexual. La internalización de la homofobia nace desde la conciencia o inconciencia que tiene el homosexual acerca de su orientación o identidad sexual, debido al impacto en su subjetividad de las homofobias antes descritas.

Por eso en la adolescencia fui mi propia víctima, al estudiar varios años en un colegio femenino, resultó inevitable verme inmersa en un mundo que desconocía y al cual le temía, descubrí que mis amigas más cercanas mantenían relaciones afectivas con otras chicas, develando ante mis ojos una sexualidad diferente y trasgresora a la convencional. Lo cual sembró en mí, pensamientos contradictorios acerca del amor y la manera correcta de vivirlo. Sin darme cuenta el hacer explicita la orientación sexual de mis amigas estaba implicando descubrir la mía, la cual fue consolidándose de una manera más seria en la medida que me sentía muy atraída hacia una de mis amigas.

Fue el peor año de mi vida, me "enamoré" de quien menos habría pensado en la vida, me hice daño de muchas maneras, escondiendo mis sentimientos, llorando todas las noches en silencio por ese amor que, aunque pudiera ser correspondido, no dejaba de mirar como incorrecto, reprochándoles con odio a las lesbianas su condición humana. Condición que desde entonces siento totalmente mía, perdí gran interés en el estudio y en las relaciones sociales, haciéndome cada vez más introvertida e insegura y perdiendo finalmente el primer y único grado escolar en mi vida académica, hablo del décimo grado. Tuve que aprender a lidiar un par de años con mi propia homofobia hasta entender que esta no era "un punto de vista diferente" como yo me obligaba a verlo, sino que es una agresión contra mi propia comunidad.

Según lo explicado anteriormente, sobre los tipos de homofobias y sus expresiones, puedo resaltar como principales consecuencias de la homofobia, para la comunidad LGBT: la exclusión social, la violencia física y verbal, los homicidios, la discriminación sistemática en el ámbito laboral, social, educativo, incluso familiar, las diferentes barreras en el acceso a derechos fundamentales, la invisibilización y el menosprecio. Pero no he mencionado, a mi modo de ver, la consecuencia más devastadora de todas estas formas de dañarnos, hablo del suicidio. De acuerdo con lo expresado en un periódico chileno, (Tasa de suicidio en jóvenes LGBTI es cuatro veces mayor que en el resto de la población, 2017), es posible determinar cómo las distintas homofobias a las que estamos expuestos pasan de ser un "factor de riesgo" a ser una "causa determinante" del suicidio. A 
través de la "Encuesta Nacional de Clima Escolar en Chile", realizada por la fundación "Todo Mejora", se pudo evidenciar esta problemática, la cual incluso puede aumentar ocho veces más que en el resto de la población, cuando existe un rechazo familiar por motivos de orientación o identificación sexual.

Hablando de este tema es imperdonable no hacer referencia al suicidio de Sergio Urrego, el cual fue inducido a causa bullying escolar por ser gay. Digo que es imperdonable no mencionar este caso porque en realidad enlutó a toda nuestra comunidad y porque, aunque fue demasiado drástica la medida tomada por Urrego, tenía de fondo un increíble y valeroso fin, ya que se sacrifica como mártir por nuestra comunidad, abriendo un debate serio acerca de la discriminación sexual en los colegios.

Aunque el objetivo fundamental de este ensayo es cuestionar las tecnologías de género y sus estrategias para la perpetuación errónea de un solo estilo de vida "real y correcto" (la heterosexualidad), termino mi trabajo mencionando la manera en que nuestra comunidad ha ido respondiendo a tanto desconocimiento, violencia e intolerancia.

Es sabido que el abuso del poder, junto con la violación de derechos humanos, son motivos de peso para que las personas directamente afectadas busquen organizarse, de manera que puedan emprender acciones útiles para mitigar y luchar contra aquellas fuerzas que las oprimen. En el caso de nuestra lucha no es diferente. Desde el colectivo colombiano León Zuleta, un grupo de personas lesbianas, gays, bisexuales y trans estudia y reflexiona para accionar y producir artística y cognitivamente sobre la diversidad y liberación de la sexualidad en la sociedad. Con aportes a la construcción de sujetos sociales y políticos se escribe acerca de la historia del movimiento homosexual en nuestro país, con sus principales líderes, grupos, tendencias, publicaciones y acontecimientos políticos.

Por ejemplo, es notable que, a partir de la década del 90 después de la despenalización de la condición de homosexualidad en 1980 y la eliminación de los manuales diagnósticos de psiquiatría de la homosexualidad como patología mental, empiezan a surgir muchas y más diversas organizaciones; así, por ejemplo, en el movimiento lésbico encontramos: Triángulo Negro, Mujeres al Borde, Colectivo Lésbico, Fundación Mujeres de Ébano. En el movimiento gay: Edipogay, Colectivo Gay de Medellín, Amigos Comunes, Grupo de Apoyo Oasis, Rostros de Fortalezas; y aparecen también colectivos de apoyo a grupos y personas objeto de discriminación sexual de mayor individualización como la Red de Apoyo a Transgeneristas.

Mientras algunas de estas organizaciones se han orientado hacia una discusión teórica sobre la diversidad sexual y los derechos sexuales como derechos humanos, otras han trabajado en el fortalecimiento de la acción legal mediante la conformación de un equipo multidisciplinario, donde los logros obtenidos han sido significantes, como los mismos derechos patrimoniales en comparación con las parejas heterosexuales, el cambio del sexo en la cedula de ciudadanía y el matrimonio igualitario por mencionar algunos. Esto no indica que las leyes sean cumplidas o que por la homofobia de los funcionarios de la ley no se nos pongan barreras agotadoras para acceder a nuestros derechos. Pero significa, al menos, que podemos ir transformando las leyes que nos gobiernan, leyes que, si bien no se cumplen rigurosamente, al menos ya no nos desconocen y nos respaldan.

Ha sido un camino de no acabar nuestra lucha contra el discurso homofóbico y sus repercusiones en nuestra comunidad, y nos queda aún mucho más por recorrer. Pero vamos caminando. Somos una comunidad GRANDE llena de amor y buenas ideas para transformar la sociedad, por una donde el respeto a la diversidad es fundamental para el libre desarrollo de la personalidad de las personas y las buenas relaciones sociales. Somos una comunidad llena de valentía para defender nuestros ideales, que pese al miedo y al odio que lanzan sobre nosotros, responde y se defiende. 


\section{Referencias bibliográficas}

Blanco, A. M. (2000). Los Modelos Pedagógicos. Instituto de Educación a Distancia de la Universidad del Tolima, 7.

Boswell, J. (1998). Cristianismo, Tolerancia Social y Homosexualidad, Los gays en Europa occidental desde el comienzo de la Era Cristiana hasta el siglo XIV. Barcelona: Muchnik Editores.

Butler, J. (2007). El género en disputa. Barcelona: Paidós.

Comisión Interamericana de derechos humanos. (2015). Violencia contra Personas Lesbianas, Gays, Bisexuales, Trans e Intersex en América.

Defensoría del Pueblo. (2016). Vigésimo Cuarto Informe del Defensor del Pueblo al Congreso de la República de Colombia. Bogotá.

Dover, K. J. (2008). Homosexualidad griega. Barcelona: El Cobre Ediciones.

Estudios demuestran que orinar sentado beneficia la salud de los hombres. (11 de marzo de 2015). El Universal. doi:http://www. eluniversal.com.co/salud/estudios-demuestranque-orinar-sentado-beneficia-la-salud-de-loshombres- 187230

Fernández, E. C. (2010). Reseña, Historia de la sexualidad 1: La voluntad del saber de Michael Foucault. Sapiens. Revista Universitaria de Investigación.

Foucault, M. (2012). Historia de la sexualidad I: la voluntad de saber. Madrid: Biblioteca Nueva.

Foucault, M. (2008). Tecnologías del yo y otros textos afines. Pensamiento contemporáneo. Buenos Aires: Paidós Ibérica, S.A.

La Congregación para la Doctrina de la fe. (1986). Carta a los obispos de la iglesia católica sobre la atención pastoral a las personas homosexuales. Roma.

La esperanza de vida en Latinoamérica llegó a los 74 años. (27 de septiembre de 2017). La Nación. doi:https://www.lanacion.com. ar/1510105-esperanza-vida

Lauretis, T. d. (1989). Tecnologías de género. Ensayos sobre teoría, cine y ficción. http://blogs.fad. unam.mx/asignatura/adriana_raggi/wpcontent/ uploads/2013/12/teconologias-del-generoteresa-de-lauretis.pdf

Llamas, R. (1998). Teoría torcida prejuicios y discursos en torno a "la homosexualidad". Madrid: Siglo XXI.

Preciado, B. (s.f). Basura y género. Mearl Cagar. Masculino/Femenino. http://www.iztacala. unam.mx/errancia/v0/PDFS/POLIETICAS $\% 20$ DEL\%20CUERPO\%201\%20BASURA\%20Y\%20 GENERO.pdf

Rehbein, C. (14 de marzo de 2017). Tasa de suicidio en jóvenes LGBTI es cuatro veces mayor que en el resto de la población. Publimetro. doi:https://todomejora.org/publimetro-tasade-suicidio-en-jovenes-lgbti-es-cuatro-vecesmayor-que-en-el-resto-de-la-poblacion/

Rich, A. (1996). Heterosexualidad obligatoria y existencia lesbiana. DUODA Revista d'Estudis Feministes núm 10

Rodríguez, K. (28 de febrero de 2018). El trascendental caso de una profesora trans en colegio del Valle del Cauca. El espectador. doi:https://www.elespectador.com/noticias/ nacional/valle/padres-de-estudiantes-decolegio-publico-en-tulua-piden-que-despidanprofesora-por-ser-trans-articulo-741834

Sedgwick, E. K. (1998). Epistemología del armario. Barcelona: Ediciones de la Tempestad. 


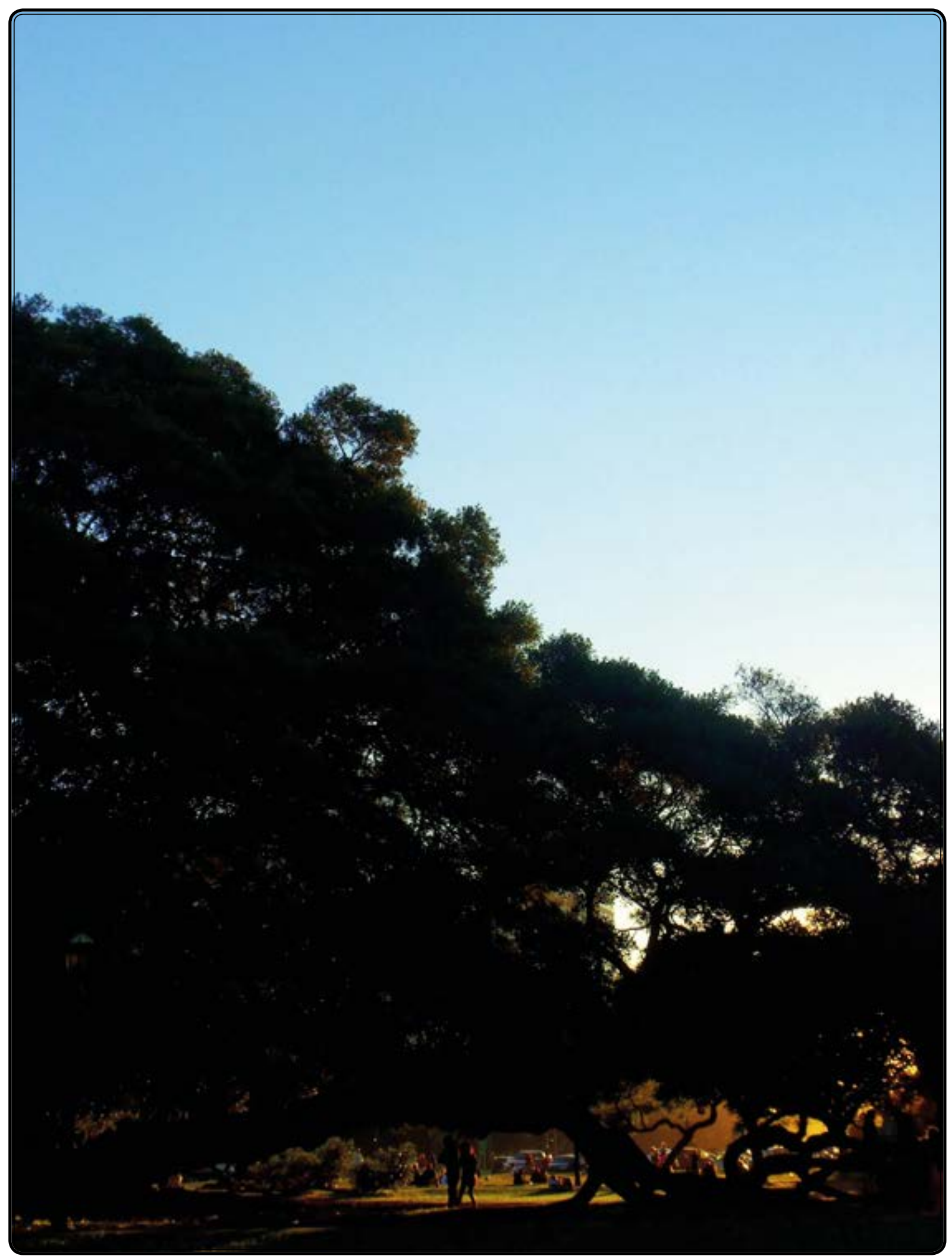

Irregularidad de las sombras 